\title{
Thermal response of electronic, optical, mechanical properties, phonon frequencies, and sound velocity of InPxAsySb1-x-y/InAs quaternary semiconductor system
}

\section{A R Degheidy}

Mansoura University

\section{A M AbuAli}

Zewail City of Science and Technology

Elkenany B Elkenany ( $\sim$ kena@mans.edu.eg )

Mansoura University Faculty of Science https://orcid.org/0000-0002-3700-1598

\section{Research Article}

Keywords: Optical properties, Acoustic velocities, Phonon frequencies, Mechanical properties, InPxAsySb1-x-y/InAs alloys

Posted Date: January 13th, 2022

DOl: https://doi.org/10.21203/rs.3.rs-980155/v1

License: (c) (1) This work is licensed under a Creative Commons Attribution 4.0 International License.

Read Full License 


\title{
Thermal response of electronic, optical, mechanical properties, phonon frequencies, and sound velocity of InPxAsySb1-x-y/InAs quaternary semiconductor system
}

\author{
A. R. Degheidy ${ }^{1}$, A. M. AbuAli², Elkenany. B. Elkenany ${ }^{1 *}$ \\ ${ }^{1}$ Department of Physics, Faculty of Science, Mansoura University, P. O. Box: 35516, Mansoura, Egypt \\ ${ }^{2}$ University of Science and Technology, Zewail City of Science and Technology, P. O. Box: 12578, October \\ City, Giza, Egypt \\ "E-mail: kena@mans.edu.eg
}

\begin{abstract}
The temperature dependence of acoustic velocities, thermal properties, and phonon frequencies, mechanical, electronic, and optical properties for the $\mathrm{InP}_{\mathrm{x}} \mathrm{As}_{\mathrm{y}} \mathrm{Sb}_{1-\mathrm{x}-\mathrm{y}} / \mathrm{InAs}$ system has been studied. The physical properties of the binary components InSb, InP, and InAs that constitute the quaternary alloy were used in this research. The study has been done using the empirical pseudo-potential method (EPM) under the virtual crystal approximation (VCA). The thermal properties, phonon frequencies, and acoustic velocities for the $\mathrm{InP}_{\mathrm{x}} \mathrm{As}_{\mathrm{y}} \mathrm{Sb}_{1-\mathrm{x}-\mathrm{y}} / \mathrm{InAs}$ system under the effect of temperature have not been fully studied. Therefore, we have focused on these properties under the influence of temperature. Due to the lack of the published theoretical and experimental values on these properties, our findings will provide a significant reference for future experimental work.
\end{abstract}

Keywords: Optical properties, Acoustic velocities, Phonon frequencies, Mechanical properties, $\mathrm{InP}_{\mathrm{x}} \mathrm{As}_{\mathrm{y}} \mathrm{Sb}_{1-\mathrm{x}-\mathrm{y}} / \mathrm{InAs}$ alloys 


\section{Introduction}

Among all semiconductor materials, the III-V semiconductors family is of great importance due to the variety of its applications. The III-V family is used in making very efficient optoelectronic devices of high-speed electron mobility, small binding energy, and direct energy band gaps (Adachi 2009; Adachi 2005). Quaternary alloys built using the III-V semiconductors are highly important, this is because they are methods to tune the value of band gaps to enhance the workings of the high-speed optoelectronic devices (Adachi 2009; Adachi 2005). This alloy is used to manufacture high-quality optical fibers in the range of 2$4 \mu \mathrm{m}$ and TPV cells that are working in the range of 0.35 to $0.5 \mathrm{eV}$ (Adachi 2009; Adachi 2005).

Manufacturing the $\operatorname{InP}_{x} \mathrm{Ass}_{\mathrm{y}} \mathrm{Sb}_{1-\mathrm{x}-\mathrm{y}}$ can be done using lattice matching with either InAs or GaSb as substrate [2]. Numerous methods have been utilized to study the band-structure of semiconductors; among them is the so-called EPM (Chelikowsky and Cohen 1976; Degheidy et al. 2017; Degheidy and Elkenany 2017; Pandey and Phillips 1974). The temperature and pressure dependence of the physical properties for the alloys has been recorded theoretically and experimentally by several works (Chen and Ravindra 2012; Degheidy et al. 2012; Degheidy and Elkenany 2013a; Degheidy and Elkenany 2013b; Degheidy and Elkenany 2011; Elkenany 2015; Saib et al. 2008; Wang et al. 2012; Yang et al. 2021). This area of research is still active and growing. Although that, we do understand the physical concepts behind these quaternary semiconductors, there is a great need to have more accurate values for the parameters used in practical applications. The III-V quaternary alloy under study in this research is based on the binary compounds InP, InAs, and InSb.

In this study, we adopted InAs as a substrate to make a theoretical and computational study using the EPM technique within the validity of the VCA to give a prediction of the 
temperature dependence of the physical parameters of this quaternary alloy. The input parameters of the calculations can be derived from the corresponding values of the binary compounds that form the quaternary alloy using the appropriate interpolation scheme.

The basic parameters of the $\operatorname{InP}_{x} A_{y} S_{1-x-y}$ quaternary alloy, such as the energy band gaps, mechanical parameters, thermal properties, phonon frequencies, speed of sound and optical properties, and their temperature dependence have been studied. To the best of our knowledge, this work has not been well-reported in the literature, so this research is an attempt to add value to the literature in that arena.

\section{Computational method}

The electronic properties of the quaternary alloy system of interest were calculated by using the (EPM) within (VCA) (Chelikowsky and Cohen 1976; Degheidy et al. 2017; Degheidy and Elkenany 2017; Pandey and Phillips 1974). According to the (VCA) and Vegard's law (Vegard 1921), the lattice constants and pseudo-potential form factors for the quaternary alloys $\mathrm{InP}_{\mathrm{x}} \mathrm{As}_{\mathrm{y}} \mathrm{Sb}_{1-\mathrm{x}-\mathrm{y}}$ could be created in the form of the linear combinations,

$$
\begin{aligned}
& \mathrm{a}_{\mathrm{InP}_{\mathrm{X}} \mathrm{As}_{\mathrm{y}} \mathrm{Sb}_{1-\mathrm{x}-\mathrm{y}}}=\mathrm{xa}_{\mathrm{InP}}+\mathrm{ya}_{\mathrm{InAs}}+(1-\mathrm{x}-\mathrm{y}) \mathrm{a}_{\mathrm{InSb}} \\
& \mathrm{W}_{\mathrm{InP}_{\mathrm{X}} \mathrm{As}_{\mathrm{y}} \mathrm{Sb}_{1-\mathrm{x}-\mathrm{y}}}=\mathrm{xW}_{\mathrm{InP}}+\mathrm{yW} \mathrm{W}_{\mathrm{InAs}}+(1-\mathrm{x}-\mathrm{y}) \mathrm{W}_{\mathrm{InSb}}
\end{aligned}
$$

The lattice match condition for $\mathrm{InP}_{\mathrm{x}} \mathrm{As}_{\mathrm{y}} \mathrm{Sb}_{1-\mathrm{x}-\mathrm{y}}$ on InAs substrate was given as follows (Adachi 2005):

$x=0.68933-0.68933 \mathrm{y}, 0 \leq \mathrm{x} \leq 1$

The elastic constants $\mathrm{C}_{11}, \mathrm{C}_{12}, \mathrm{C}_{44}$ of the studied alloys and their related parameters such as bulk $\mathrm{B}_{\mathrm{u}}$, shear $\mathrm{S}_{\mathrm{h}}$, and Young's $\mathrm{Y}_{0}$ moduli could be determined by knowing the polarities (Baranowski 1984; Bouarissa 2003; Harrison 1980; Shen 1994). The density of crystal (g) 
and the elastic constants $\left(\mathrm{c}_{\mathrm{ij}}\right)$ were utilized to determine the velocity of sound as (Adachi 2005):

$$
\mathrm{v}=\sqrt{\frac{c_{i j}}{g}}
$$

The refractive index, high frequency, and static dielectric constants could be determined as in Refs. (Adachi 2005; Davydov and Tikhonov 1998; Moss 1950; Samara 1983). The optical phonon frequencies of the alloy of interest $\omega_{\mathrm{LO}}$ and $\omega_{\mathrm{TO}}$ could be obtained as in Refs. (Davydov and Tikhonov 1998; Kittel and McEuen 1976)

$\frac{\omega_{T O}^{2}}{\omega_{L O}^{2}}=\frac{\varepsilon_{\infty}}{\varepsilon_{S}}$

$\omega_{L O}^{2}-\omega_{T O}^{2}=\frac{4 \pi e_{T}^{* 2} e^{2}}{M \Omega_{o} \varepsilon_{\infty}}$

Where $\mathrm{M}$ is twice of reduced mass and $\Omega_{\mathrm{o}}$ is the volume occupied by one atom. By knowing the longitudinal phonon frequency, Debye temperature $\theta_{D}$, the heat capacity could be determined as in Refs. (Adachi 2005; Adachi 1985).

\section{Results and discussions}

The electronic energy band gaps of $\operatorname{InP}_{x} \mathrm{As}_{y} \mathrm{Sb}_{1-\mathrm{x}-\mathrm{y}}$ alloys lattice-matched to InAs were calculated throughout the high-symmetry points $\mathrm{L}, \Gamma$, and $\mathrm{X}$ in the Brillouin zone. The dependence of the energy gaps of the $\mathrm{InP}_{\mathrm{x}} \mathrm{As}_{\mathrm{y}} \mathrm{Sb}_{1-\mathrm{x}-\mathrm{y}} / \mathrm{InAs}$ system on temperature from 0 to $500 \mathrm{~K}$ at specified values of the $\mathrm{y}$-composition parameter $(0.2,0.6,1)$ is listed in Table 1 and displayed in Fig. 1. Our findings are in excellent agreement with the published values at room temperature at $\mathrm{y}=1$ (InAs) (Boucenna et al. 2014; Degheidy et al. 2018). At a higher temperature, our results may serve as references for future experimental work. It can be seen that the energy gaps at the $\Gamma, \mathrm{L}$, and $\mathrm{X}$ points are decreased by enhancing temperature at various compositions $(0.2,0.6,1)$. Also, we have noticed that the energy band gaps 
$E_{g}^{L}, E_{g}^{\Gamma}, E_{g}^{X}$ are shifted downward with the composition from 0.2 to 1 . This means that they $.500 \mathrm{~K})$-in the temperature range (0 enhancing composition byare decreased $E_{g}^{L}, E_{g}^{\Gamma}, E_{g}^{X}$

The curves in Fig. 1 can be fitted by the following polynomials:

For $\mathrm{y}=0.2,\left\{\begin{array}{l}E_{g}^{L}(T)=E_{g}^{L}(0)-\left(0.0008-4 * 10^{-8} T\right) T \\ E_{g}^{\Gamma}(T)=E_{g}^{\Gamma}(0)-\left(0.0004-8 * 10^{-8} T\right) T \\ E_{g}^{X}(T)=E_{g}^{X}(0)-\left(0.0011-6 * 10^{-8} T\right) T\end{array}\right\}$

For y $=0.6,\left\{\begin{array}{l}E_{g}^{L}(T)=E_{g}^{L}(0)-\left(0.0008-5 * 10^{-8} T\right) T \\ E_{g}^{\Gamma}(T)=E_{g}^{\Gamma}(0)-\left(0.0003-2 * 10^{-9} T\right) T \\ E_{g}^{X}(T)=E_{g}^{X}(0)-\left(0.0011-1 * 10^{-7} T\right) T\end{array}\right\}$

For $\mathrm{y}=1,\left\{\begin{array}{l}E_{g}^{L}(T)=E_{g}^{L}(0)-\left(0.0008-1 * 10^{-7} T\right) T \\ E_{g}^{\Gamma}(T)=E_{g}^{\Gamma}(0)-\left(0.0003-4 * 10^{-8} T\right) T \\ E_{g}^{X}(T)=E_{g}^{X}(0)-\left(0.001-5 * 10^{-8} T\right) T\end{array}\right\}$

Table 1 The energy gaps of $\mathrm{InP}_{\mathrm{x}} \mathrm{As}_{\mathrm{y}} \mathrm{Sb}_{1-\mathrm{x}-\mathrm{y}} / \mathrm{InAs}$ system at various temperatures at different values of ycomposition parameter $(0.2,0.6,1)$

\begin{tabular}{|c|c|c|c|c|c|c|c|c|c|}
\hline \multirow[b]{2}{*}{$\mathrm{T}(\mathrm{K})$} & \multicolumn{3}{|c|}{$\mathrm{y}=0.2$} & \multicolumn{3}{|c|}{$y=0.6$} & \multicolumn{3}{|c|}{$y=1$} \\
\hline & $\mathrm{E}_{\mathrm{g}}^{\mathrm{L}}(\mathrm{eV})$ & $\mathrm{E}_{\mathrm{g}}{ }^{\Gamma}(\mathrm{eV})$ & $\mathrm{E}_{\mathrm{g}} \mathrm{X}(\mathrm{eV})$ & $\mathrm{E}_{\mathrm{g}}^{\mathrm{L}}(\mathrm{eV})$ & $\mathrm{E}_{\mathrm{g}}^{\Gamma}(\mathrm{eV})$ & $\mathrm{E}_{\mathrm{g}} \mathrm{X}_{(\mathrm{eV})}$ & $\mathrm{E}_{\mathrm{g}}^{\mathrm{L}}(\mathrm{eV})$ & $\mathrm{E}_{\mathrm{g}}^{\Gamma}(\mathrm{eV})$ & $\mathrm{E}_{\mathrm{g}} \mathrm{X}(\mathrm{eV})$ \\
\hline 0 & 1.73 & 0.99 & 2.28 & 1.51 & 0.69 & 2.04 & 1.28 & 0.44 & 1.81 \\
\hline 100 & 1.65 & 0.95 & 2.17 & 1.43 & 0.66 & 1.93 & 1.20 & 0.41 & 1.71 \\
\hline 200 & 1.57 & 0.91 & 2.06 & 1.36 & 0.63 & 1.82 & 1.12 & 0.39 & 1.61 \\
\hline 300 & 1.50 & 0.87 & 1.95 & 1.28 & 0.60 & 1.72 & $\begin{array}{l}1.05 \\
1.07^{\mathrm{a}}\end{array}$ & $\begin{array}{c}0.36 \\
0.360^{\mathrm{a}}\end{array}$ & $\begin{array}{l}1.51 \\
1.51^{\mathrm{b}}\end{array}$ \\
\hline 400 & 1.42 & 0.83 & 1.84 & 1.20 & 0.56 & 1.62 & 0.98 & 0.34 & 1.41 \\
\hline 500 & 1.34 & 0.79 & 1.73 & 1.13 & 0.53 & 1.52 & 0.91 & 0.31 & 1.32 \\
\hline
\end{tabular}

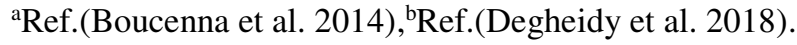



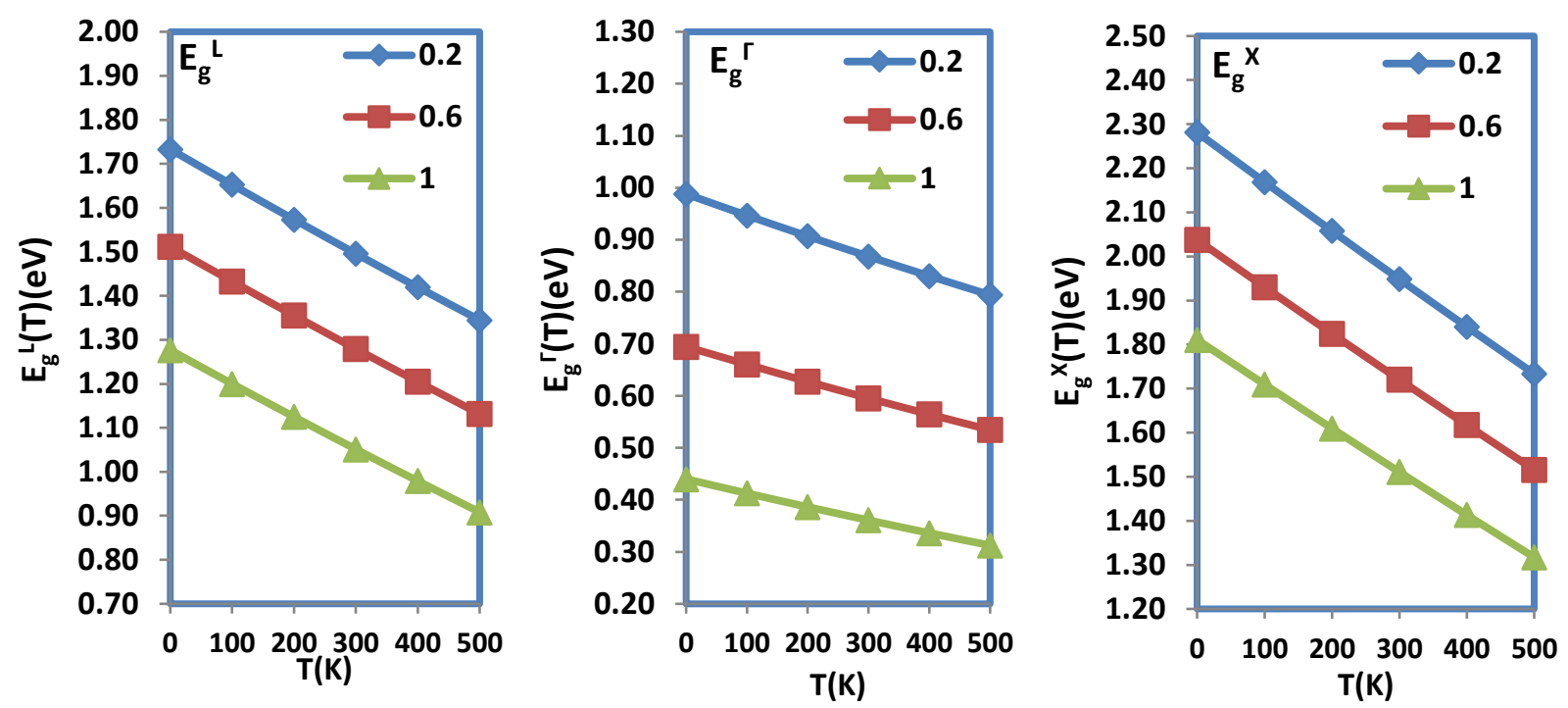

Fig. 1 The energy gaps of $\operatorname{InP}_{x} A s_{y} S_{1-x-y} / I n A s$ system as function of temperature at different values of $y$ composition parameter $(0.2,0.6,1)$

In designing and manufacturing optoelectronic devices such as solar cells and waveguides detectors, the refractive index and optical dielectric constants are very essential. The variation of refractive index, static and high-frequency dielectric constants of the $\mathrm{InP}_{\mathrm{x}} \mathrm{Asy}_{\mathrm{y}} \mathrm{Sb}_{1-\mathrm{x}-\mathrm{y}} / \mathrm{InAs}$ system with the temperature for compositions $(0.2,0.6,1)$ is displayed in Fig. 2. It is observed that all the studied optical properties are increased by enhancing temperature for the compositions $(0.2,0.6,1)$. Moreover, the refractive index, static and highfrequency dielectric constants of the $\mathrm{InP}_{\mathrm{x}} \mathrm{As}_{\mathrm{y}} \mathrm{Sb}_{1-\mathrm{x}-\mathrm{y}} / \mathrm{InAs}$ system are increased with enhancing composition over the whole region of temperature. This is due to, the inverse relation between the electronic band gaps and refractive index. Since the energy band gaps are decreased by increasing the temperature. 

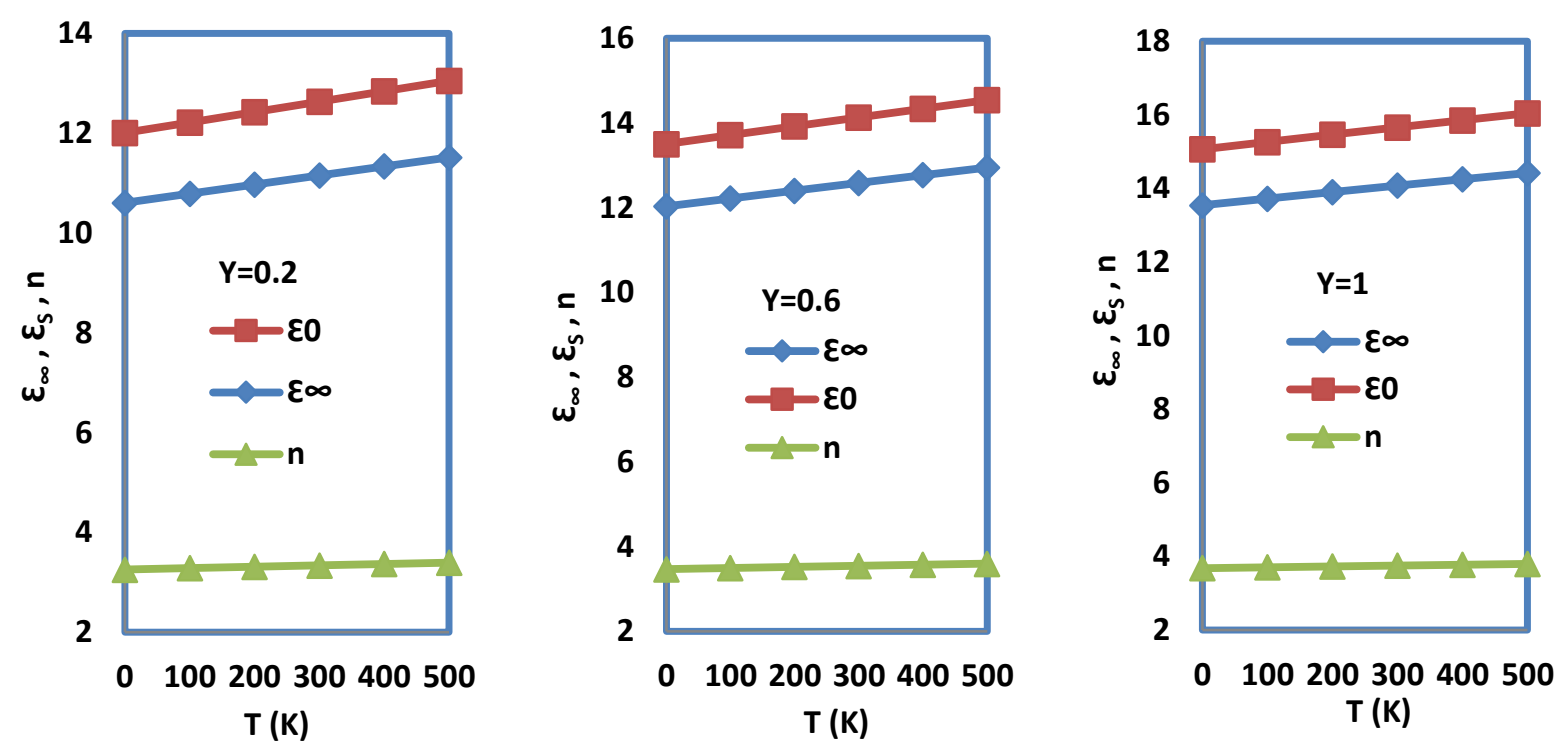

Fig. 2 The refractive index, high frequency and static dielectric constants of $\operatorname{InP}_{x} A_{y} S_{1-x-y} / \operatorname{InAs}$ system as function of temperature at compositions $(0.2,0.6$ and 1$)$

The mechanical moduli play a vital role in giving useful data on the structural stability and anisotropic binding characteristics. Table 2 and Fig. 3 provide the dependence of elastic constants $\left(\mathrm{C}_{11}, \mathrm{C}_{12}, \mathrm{C}_{44}, \mathrm{~B}_{\mathrm{u}}, \mathrm{S}_{\mathrm{h}}\right.$, and $\left.\mathrm{Y}_{0}\right)$ on temperature for the $\mathrm{InP}_{\mathrm{x}} \mathrm{As}_{\mathrm{y}} \mathrm{Sb}_{1-\mathrm{x}-\mathrm{y}} / \mathrm{InAs}$ system at different values of $\mathrm{y}(0.2,0.6$, and 1$)$. For $\mathrm{y}=1$ (InAs) at $\mathrm{T}=300 \mathrm{~K}$, the calculated $\mathrm{C}_{11}, \mathrm{C}_{12}$, $\mathrm{C}_{44}, \mathrm{~B}_{\mathrm{u}}, \mathrm{S}_{\mathrm{h}}$, and $\mathrm{Y}_{0}$ are in excellent accord with the published values (Algarni et al. 2018). The calculated $\mathrm{C}_{11}, \mathrm{C}_{12}, \mathrm{C}_{44}, \mathrm{~B}_{\mathrm{u}}, \mathrm{S}_{\mathrm{h}}$, and $\mathrm{Y}_{0}$ at the other values of temperature for $\mathrm{y}=0.2$ and 0.6 can be taken as references for the experimental data. It is noticed that $\mathrm{C}_{11}, \mathrm{C}_{12}, \mathrm{C}_{44}, \mathrm{~B}_{\mathrm{u}}, \mathrm{S}_{\mathrm{h}}$, and $\mathrm{Y}_{0}$ are decreased by increasing temperature. Besides, these moduli are increased with increasing compositions over the temperature range from 0 to $500 \mathrm{~K}$. The conditions of stability were given by knowing the elastic constants as in Ref. (Zhang et al. 2012). Our results display that $\mathrm{C}_{11}(\mathrm{~T})-\mathrm{C}_{12}(\mathrm{~T})>0, \mathrm{C}_{11}(\mathrm{~T})>0, \mathrm{C}_{44}(\mathrm{~T})>0, \mathrm{C}_{11}(\mathrm{~T})+2 \mathrm{C}_{12}(\mathrm{~T})>0$, which achieve the stability of the $\mathrm{InP}_{x} \mathrm{As}_{\mathrm{y}} \mathrm{Sb}_{1-\mathrm{x}-\mathrm{y}} / \mathrm{InAs}$ system in its structure over the studied range of temperature. Pugh (Pugh 1954) introduced an important formula that distinguishes between the ductile and brittle properties of materials, i.e. the material acts ductility if $B_{u} / S_{h}>1.75$; otherwise the material acts in a brittle way. From our results, the $\operatorname{InP}_{x} A_{s y} S_{1-x-y} / \operatorname{InAs}$ system 
has a ductile behavior over the temperature range $(0-500 \mathrm{~K})$. This is because the calculated values of $\mathrm{B}_{\mathrm{u}} / \mathrm{S}_{\mathrm{h}}$ over the temperature range $(0-500 \mathrm{~K})$ for compositions $(0.2,0.6$ and 1$)$ are greater than 1.75 .

Table 2 Mechanical parameters $\left(\mathrm{C}_{11}, \mathrm{C}_{12}, \mathrm{C}_{44}, \mathrm{~B}_{\mathrm{u}}, \mathrm{S}_{\mathrm{h}}\right.$ and $\left.\mathrm{Y}_{0}\right)$ in $\left(10^{12} \mathrm{dyn} / \mathrm{cm}^{2}\right)$ of $\mathrm{InP}_{\mathrm{x}} \mathrm{As}_{\mathrm{y}} \mathrm{Sb}_{1-\mathrm{x}-\mathrm{y}} / \mathrm{InAs}$ system at various temperatures for compositions $(0.2,0.6$ and 1$)$

\begin{tabular}{|c|c|c|c|c|c|c|c|c|c|c|c|c|c|c|c|c|c|c|}
\hline \multirow{2}{*}{$\mathrm{T}(\mathrm{K})$} & \multicolumn{6}{|c|}{$\mathrm{y}=0.2$} & \multicolumn{6}{|c|}{$\mathrm{y}=0.6$} & \multicolumn{6}{|c|}{$y=1$} \\
\hline & $\mathrm{C}_{11}$ & $\mathrm{C}_{12}$ & $\mathrm{C}_{44}$ & $\mathrm{~B}_{\mathrm{u}}$ & $\mathrm{S}_{\mathrm{h}}$ & $\overline{\mathrm{Y}_{0}}$ & $\mathrm{C}_{11}$ & $\mathrm{C}_{12}$ & $\mathrm{C}_{44}$ & $\mathrm{~B}_{\mathrm{u}}$ & $\mathrm{S}_{\mathrm{h}}$ & $\overline{Y_{0}}$ & $\mathrm{C}_{11}$ & $\mathrm{C}_{12}$ & $\mathrm{C}_{44}$ & $\mathrm{~B}_{\mathrm{u}}$ & $\mathrm{S}_{\mathrm{h}}$ & $\overline{\mathrm{Y}_{0}}$ \\
\hline 0 & 0.915 & 0.395 & 0.369 & 0.568 & 0.26 & 0.676 & 0.925 & 0.4 & 0.374 & 0.575 & 0.263 & 0.684 & 0.935 & 0.404 & 0.378 & 0.581 & 0.266 & 0.692 \\
\hline 100 & 0.912 & 0.394 & 0.368 & 0.567 & 0.259 & 0.674 & 0.923 & 0.399 & 0.373 & 0.573 & 0.262 & 0.682 & 0.933 & 0.403 & 0.377 & 0.58 & 0.265 & 0.69 \\
\hline 200 & 0.91 & 0.393 & 0.368 & 0.566 & 0.258 & 0.673 & 0.921 & 0.398 & 0.372 & 0.572 & 0.261 & 0.681 & 0.931 & 0.402 & 0.376 & 0.578 & 0.265 & 0.689 \\
\hline 300 & 0.908 & 0.392 & 0.367 & 0.564 & 0.258 & 0.671 & 0.918 & 0.397 & 0.371 & 0.571 & 0.261 & 0.679 & $\begin{array}{l}0.928, \\
0.943^{\mathrm{a}}\end{array}$ & $\begin{array}{l}0.401, \\
0.407^{\mathrm{a}}\end{array}$ & $\begin{array}{l}0.375 \\
0.381^{\mathrm{a}}\end{array}$ & $\begin{array}{l}0.577 \\
0.586^{\mathrm{a}}\end{array}$ & $\begin{array}{c}0.264 \\
2.68^{\mathrm{a}}\end{array}$ & $\begin{array}{l}0.687, \\
0.698^{\mathrm{a}}\end{array}$ \\
\hline 400 & 0.906 & 0.392 & 0.366 & 0.563 & 0.257 & 0.67 & 0.916 & 0.396 & 0.37 & 0.569 & 0.26 & 0.677 & 0.926 & 0.4 & 0.374 & 0.575 & 0.263 & 0.685 \\
\hline 500 & 0.904 & 0.391 & 0.365 & 0.562 & 0.257 & 0.668 & 0.914 & 0.395 & 0.369 & 0.568 & 0.26 & 0.676 & 0.924 & 0.399 & 0.373 & 0.574 & 0.263 & 0.683 \\
\hline
\end{tabular}

${ }^{\mathrm{a}}$ Ref.(Algarni et al. 2018).
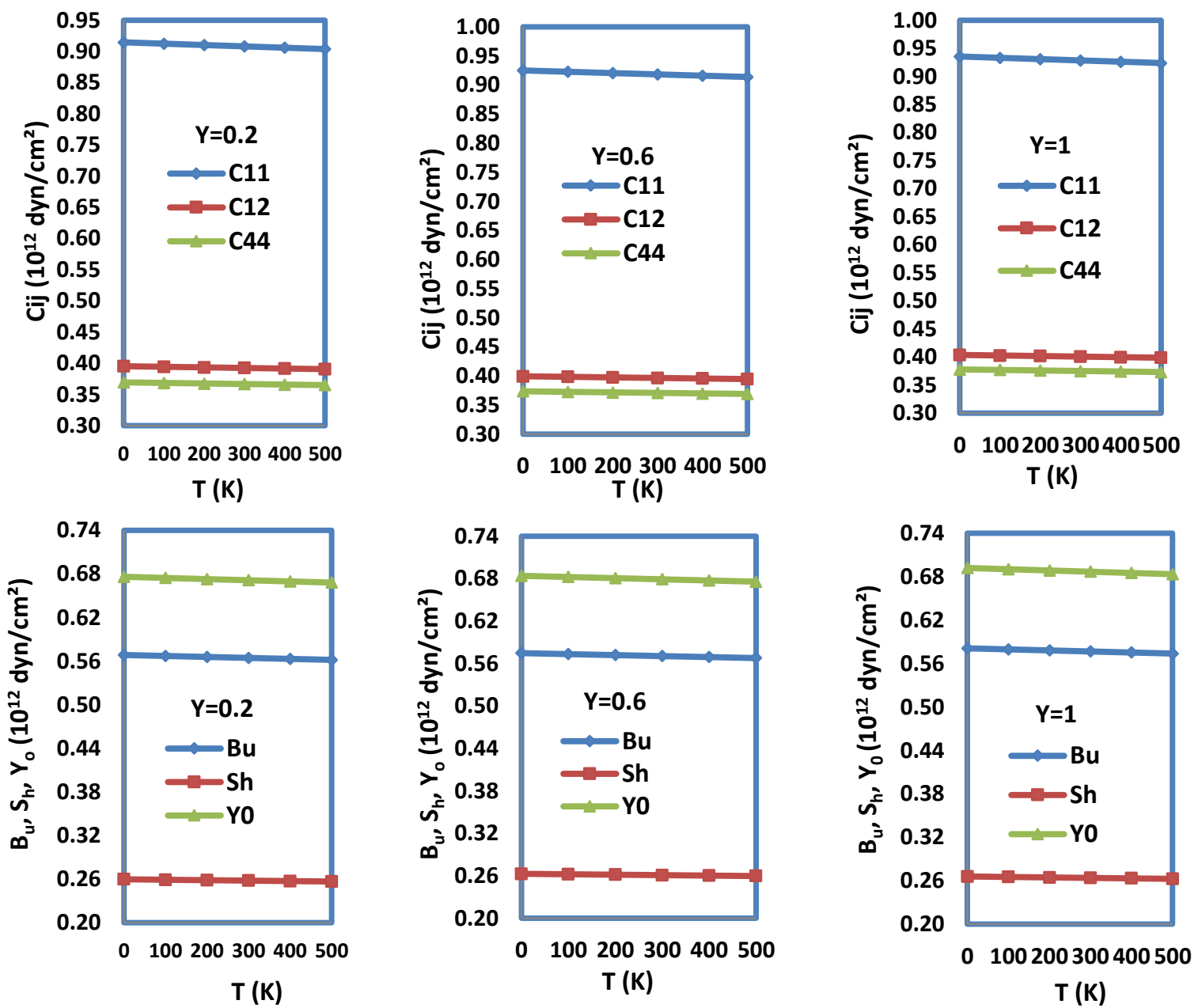

Fig. 3 Mechanical moduli $\left(\mathrm{C}_{11}, \mathrm{C}_{12}, \mathrm{C}_{44}, \mathrm{~B}_{\mathrm{u}}, \mathrm{S}_{\mathrm{h}}\right.$ and $\left.\mathrm{Y}_{0}\right)$ of $\mathrm{InP}_{\mathrm{x}} \mathrm{As}_{\mathrm{y}} \mathrm{Sb}_{1-\mathrm{x}-\mathrm{y}} / \mathrm{InAs}$ system as function of temperature at constant $\mathrm{y}$-composition parameter $(0.2,0.6$ and 1$)$ 
The variation of the sound velocities in the different directions of propagation and planes of polarization of the $\mathrm{InP}_{\mathrm{x}} \mathrm{As}_{\mathrm{y}} \mathrm{Sb}_{1-\mathrm{x}-\mathrm{y}} / \mathrm{InAs}$ system with the temperature at different values of compositions $(0.2,0.6$, and 1) are recorded in Table 3 and plotted Fig. 4. At the room temperature and $y=1$ (InAs), there is a good accord between the calculated values and the published data by Adachi (Adachi 2005). All the components of the sound velocity are slightly decreased by increasing temperature as shown in Fig. 4. Also, it can be seen that the sound velocities in the major directions [100], [110], and [111 are decreased with enhancing composition. Due to the lack of experimental data for the sound velocities of the $\operatorname{InP}_{\mathrm{x}} \mathrm{As}_{\mathrm{y}} \mathrm{Sb}_{1-}$ x-y/InAs system at different temperatures with compositions $(0.2,0.6)$, our results are predictions for future experimental work

Table 3 The sound velocities in $\left(10^{5} \mathrm{~cm} / \mathrm{Sec}\right)$ in the different directions of propagation and planes of polarization of $\mathrm{InP}_{\mathrm{x}} \mathrm{As}_{\mathrm{y}} \mathrm{Sb}_{1-\mathrm{x}-\mathrm{y}} / \mathrm{InAs}$ system at different values of compositions $(0.2,0.6$, and 1$)$

\begin{tabular}{|c|c|c|c|c|c|c|c|}
\hline \multirow[b]{2}{*}{$\mathrm{T}(\mathrm{K})$} & \multicolumn{7}{|c|}{$y=0.2$} \\
\hline & $\mathrm{V}_{100-\mathrm{LA}}$ & $\mathrm{V}_{100-\mathrm{TA} 1, \mathrm{TA} 2}$ & $\mathrm{~V}_{110 \_L A}$ & $\mathrm{~V}_{110-\mathrm{TA} 1}$ & $\mathrm{~V}_{110 \_} \mathrm{TA2}$ & $\mathrm{V}_{111-\mathrm{LA}}$ & $\mathrm{V}_{111-\mathrm{TA} 1, \mathrm{TA} 2}$ \\
\hline 0 & 4.1490 & 2.6360 & 4.3900 & 2.2100 & 2.6360 & 4.4680 & 2.3610 \\
\hline 100 & 4.1470 & 2.6350 & 4.3880 & 2.2090 & 2.6350 & 4.4660 & 2.3600 \\
\hline 200 & 4.1450 & 2.6340 & 4.3860 & 2.2080 & 2.6340 & 4.4640 & 2.3590 \\
\hline 300 & 4.1430 & 2.6330 & 4.3840 & 2.2070 & 2.6330 & 4.4620 & 2.3580 \\
\hline 400 & 4.1410 & 2.6310 & 4.3820 & 2.2060 & 2.6310 & 4.4600 & 2.3570 \\
\hline 500 & 4.1380 & 2.6300 & 4.3790 & $\begin{aligned} & 2.2050 \\
y & =0.6\end{aligned}$ & 2.6300 & 4.4570 & 2.3550 \\
\hline $\mathrm{T}$ & $\mathrm{V}_{100-\mathrm{LA}}$ & $\mathrm{V}_{100-\mathrm{TA} 1, \mathrm{TA} 2}$ & $\mathrm{~V}_{110 \_\mathrm{LA}}$ & $\mathrm{V}_{110-\mathrm{TA} 1}$ & V110_TA2 & $\mathrm{V}_{111-\mathrm{LA}}$ & $\mathrm{V}_{111-\mathrm{TA} 1, \mathrm{TA} 2}$ \\
\hline 0 & 4.0997 & 2.6056 & 4.3385 & 2.1850 & 2.6056 & 4.4152 & 2.3336 \\
\hline 100 & 4.0977 & 2.6043 & 4.3364 & 2.1839 & 2.6043 & 4.4131 & 2.3325 \\
\hline 200 & 4.0957 & 2.6031 & 4.3343 & 2.1829 & 2.6031 & 4.4109 & 2.3314 \\
\hline 300 & 4.0937 & 2.6018 & 4.3322 & 2.1818 & 2.6018 & 4.4088 & 2.3302 \\
\hline 400 & 4.0918 & 2.6006 & 4.3301 & 2.1808 & 2.6006 & 4.4067 & 2.3291 \\
\hline 500 & 4.0898 & 2.5993 & 4.3280 & $\begin{array}{l}2.1797 \\
y=1\end{array}$ & 2.5993 & 4.4045 & 2.3270 \\
\hline $\mathrm{T}$ & $\mathrm{V}_{100-\mathrm{LA}}$ & $\mathrm{V}_{100-\mathrm{TA} 1, \mathrm{TA} 2}$ & $\mathrm{~V}_{110 \_\mathrm{LA}}$ & $\mathrm{V}_{110-\mathrm{TA} 1}$ & $\mathrm{~V}_{110 \_\mathrm{TA} 2}$ & $\mathrm{~V}_{111-\mathrm{LA}}$ & $\mathrm{V}_{111-\mathrm{TA} 1, \mathrm{TA} 2}$ \\
\hline 0 & 4.0534 & 2.5765 & 4.2895 & 2.1609 & 2.5765 & 4.3653 & 2.3077 \\
\hline 100 & 4.0514 & 2.5753 & 4.2873 & 2.1598 & 2.5753 & 4.3631 & 2.3066 \\
\hline 200 & 4.0494 & 2.5740 & 4.2852 & 2.1587 & 2.5740 & 4.3610 & 2.3055 \\
\hline 300 & $\begin{array}{c}4.0474, \\
3.83^{\mathrm{a}}\end{array}$ & $\begin{array}{c}2.5727 \\
2.64^{\mathrm{a}}\end{array}$ & $\begin{array}{c}4.2831 \\
4.28^{\mathrm{a}}\end{array}$ & $\begin{array}{c}2.1576 \\
1.83^{\mathrm{a}}\end{array}$ & $\begin{array}{c}2.5727 \\
2.64^{\mathrm{a}}\end{array}$ & $\begin{array}{c}4.3588 \\
4.42^{\mathrm{a}}\end{array}$ & $\begin{array}{c}2.3043 \\
2.14^{\mathrm{a}}\end{array}$ \\
\hline 400 & 4.0454 & 2.5714 & 4.2810 & 2.1566 & 2.5714 & 4.3567 & 2.3032 \\
\hline 500 & 4.0434 & 2.5701 & 4.2788 & 2.1555 & 2.5701 & 4.3545 & 2.3020 \\
\hline
\end{tabular}

${ }^{\mathrm{a}}$ Ref.(Adachi 2005). 

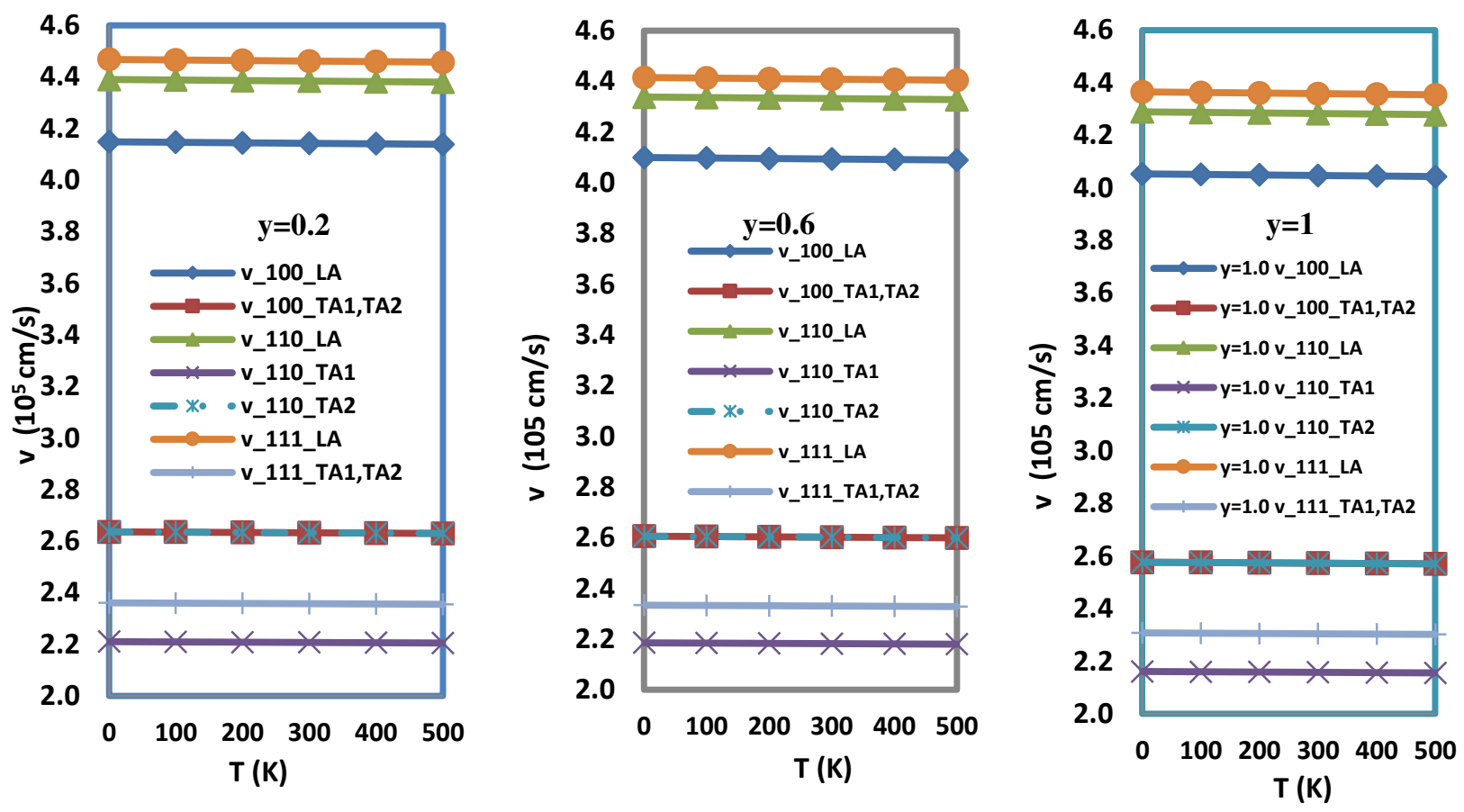

Fig. 4 The sound velocity in the different directions of propagation and planes of $\operatorname{InP}_{x} A s_{y} S_{1-x-y} / \operatorname{InAs}$ system as a function of temperature at different values of compositions $(0.2,0.6$, and 1$)$ 
The optical phonon frequencies are very useful in the study of the transport and optical properties of semiconductors. The calculated longitudinal and transversal optical phonon frequencies $\omega_{\mathrm{LO}}$ and $\omega_{\mathrm{TO}}$ of $\mathrm{InP}_{\mathrm{x}} \mathrm{As}_{\mathrm{y}} \mathrm{Sb}_{1-\mathrm{x}-\mathrm{y}} / \mathrm{InAs}$ system at various temperatures for concentrations $(0.2,0.6$, and 1$)$ are documented in Table 4 and displayed in Fig. 5. Also, the calculated values of the Debye temperature $\theta_{\mathrm{D}}$ and the molar specific heat $\mathrm{C}_{\mathrm{p}}$ of $\operatorname{InP}_{\mathrm{x}} A \mathrm{As}_{\mathrm{y}} \mathrm{Sb}_{1-\mathrm{x}-}$ y/InAs system at various temperatures with concentrations $(0.2,0.6$, and 1$)$ are listed in Table 4. At room temperature and $y=1$ (InAs), the optical phonon frequencies, Debye temperature, and the molar specific heat are found in reasonable accord with the available data in the literature (Degheidy et al. 2018; Kittel and McEuen 1976). Fig. 6 shows the variation of

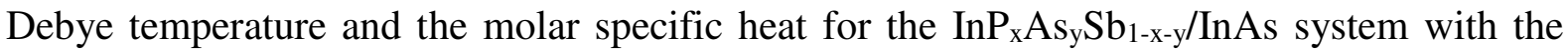
temperature at certain values of compositions $(0.2,0.6$, and 1$)$, respectively. It will be noted that the Debye temperature is decreased by increasing temperature and composition. From Fig. 6, it can be perceived that the $C_{p}$ is enhanced by increasing temperature. Also, it is seen that the $\mathrm{C}_{\mathrm{p}}$ is increased by increasing the composition. The other calculated results can be served as a reference for future experimental work. It is observed that both $\omega_{\mathrm{LO}}$ and $\omega_{\mathrm{TO}}$ are decreased by increasing temperature and composition. The curves in Fig. 5 can be fitted by the following polynomials:

$$
\begin{aligned}
& \text { At } \mathrm{y}=0.2,\left\{\begin{array}{l}
\omega_{\mathrm{LO}}(T)=\omega_{\mathrm{LO}}(0)-\left(0.0008-6 * 10^{-7} T\right) T \\
\omega_{\mathrm{TO}}(T)=\omega_{\mathrm{TO}}(0)-\left(0.0003+2 * 10^{-7} T\right) T
\end{array}\right\} \\
& \text { At } \mathrm{y}=0.6,\left\{\begin{array}{l}
\omega_{\mathrm{LO}}(T)=\omega_{\mathrm{LO}}(0)-\left(0.0002+3 * 10^{-7} T\right) T \\
\omega_{\mathrm{TO}}(T)=\omega_{\mathrm{TO}}(0)-\left(0.0007-5 * 10^{-7} T\right) T
\end{array}\right\} \\
& \text { At } \mathrm{y}=1,\left\{\begin{array}{l}
\omega_{\mathrm{LO}}(T)=\omega_{\mathrm{LO}}(0)-\left(0.0002+8 * 10^{-8} T\right) T \\
\omega_{\mathrm{TO}}(T)=\omega_{\mathrm{TO}}(0)-\left(0.0005-3 * 10^{-7} T\right) T
\end{array}\right\}
\end{aligned}
$$


Table 4 The longitudinal and transversal optical phonon frequencies ( $\omega_{\text {LO }}$ and $\left.\omega_{\text {TO }}\right)$ in $10^{13} \mathrm{~Hz}$, Debye temperature, and the molar specific heat (J/Kg.Mol) of $\mathrm{InP}_{\mathrm{x}} \mathrm{As}_{\mathrm{y}} \mathrm{Sb}_{1-\mathrm{x}-\mathrm{y}} / \mathrm{InAs}$ system for various temperatures at different compositions $(0.2,0.6$, and 1$)$

\begin{tabular}{ccccccccccccc}
\hline & \multicolumn{4}{c}{$\mathrm{y}=0.2$} & \multicolumn{4}{c}{$\mathrm{y}=0.6$} & \multicolumn{4}{c}{$\mathrm{y}=1$} \\
\cline { 2 - 12 } $\mathrm{T}(\mathrm{K})$ & $\omega_{\text {LO }}$ & $\omega_{\text {TO }}$ & $\theta_{\mathrm{D}}(\mathrm{K})$ & $\mathrm{C}_{\mathrm{p}}$ & $\omega_{\text {LO }}$ & $\omega_{\text {TO }}$ & $\theta_{\mathrm{D}}(\mathrm{K})$ & $\mathrm{C}_{\mathrm{p}}$ & $\omega_{\text {LO }}$ & $\omega_{\text {TO }}$ & $\theta_{\mathrm{D}}(\mathrm{K})$ & $\mathrm{C}_{\mathrm{p}}$ \\
\hline 0 & 5.5 & 5.1 & 416.7 & 0.0 & 4.9 & 4.7 & 376.7 & 0.0 & 4.5 & 4.3 & 344.6 & 0.0 \\
100 & 5.4 & 5.1 & 412.8 & 12.1 & 4.9 & 4.6 & 373.6 & 13.6 & 4.5 & 4.2 & 342.2 & 14.8 \\
200 & 5.4 & 5.0 & 409.1 & 20.4 & 4.9 & 4.6 & 370.6 & 21.1 & 4.4 & 4.2 & 339.8 & 21.7 \\
300 & 5.3 & 5.0 & 405.4 & 22.8 & 4.8 & 4.5 & 367.7 & 23.2 & 4.4, & 4.2, & 337.6, & 23.4, \\
& & & & & & & & & $4.5^{\mathrm{a}}$ & $4.1^{\mathrm{a}}$ & $337^{\mathrm{b}}$, & $23.3^{\mathrm{b}}$ \\
400 & 5.3 & 4.9 & 401.9 & 23.7 & 4.8 & 4.5 & 364.9 & 23.9 & 4.4 & 4.2 & 335.4 & 24.1 \\
500 & 5.2 & 4.9 & 398.5 & 24.2 & 4.7 & 4.5 & 362.2 & 24.3 & 4.4 & 4.1 & 333.3 & 24.4 \\
\hline
\end{tabular}

${ }^{\mathrm{a} R e f .(K i t t e l ~ a n d ~ M c E u e n ~ 1976), ~}{ }^{\mathrm{b}}$ Ref.(Degheidy et al. 2018).
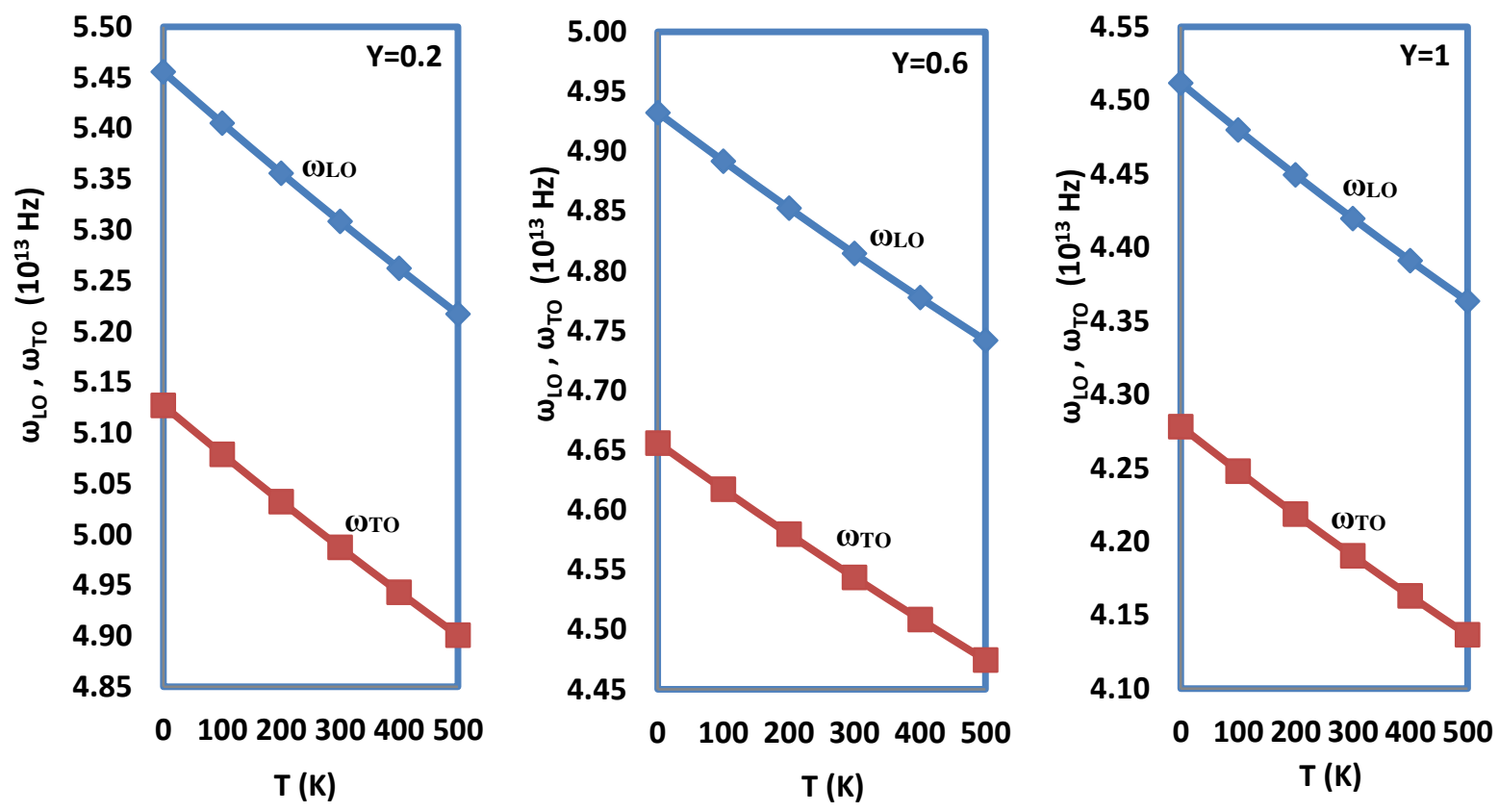

Fig. 5 The longitudinal optical phonon frequency $\omega_{\text {LO }}$ and the transversal optical phonon frequency $\omega_{\text {TO }}$ of $\mathrm{InP}_{\mathrm{x}} \mathrm{As}_{\mathrm{y}} \mathrm{Sb}_{1-\mathrm{x}-\mathrm{y}} / \mathrm{InAs}$ system as a function of temperature at certain values of compositions $(0.2,0.6$, and 1$)$ 

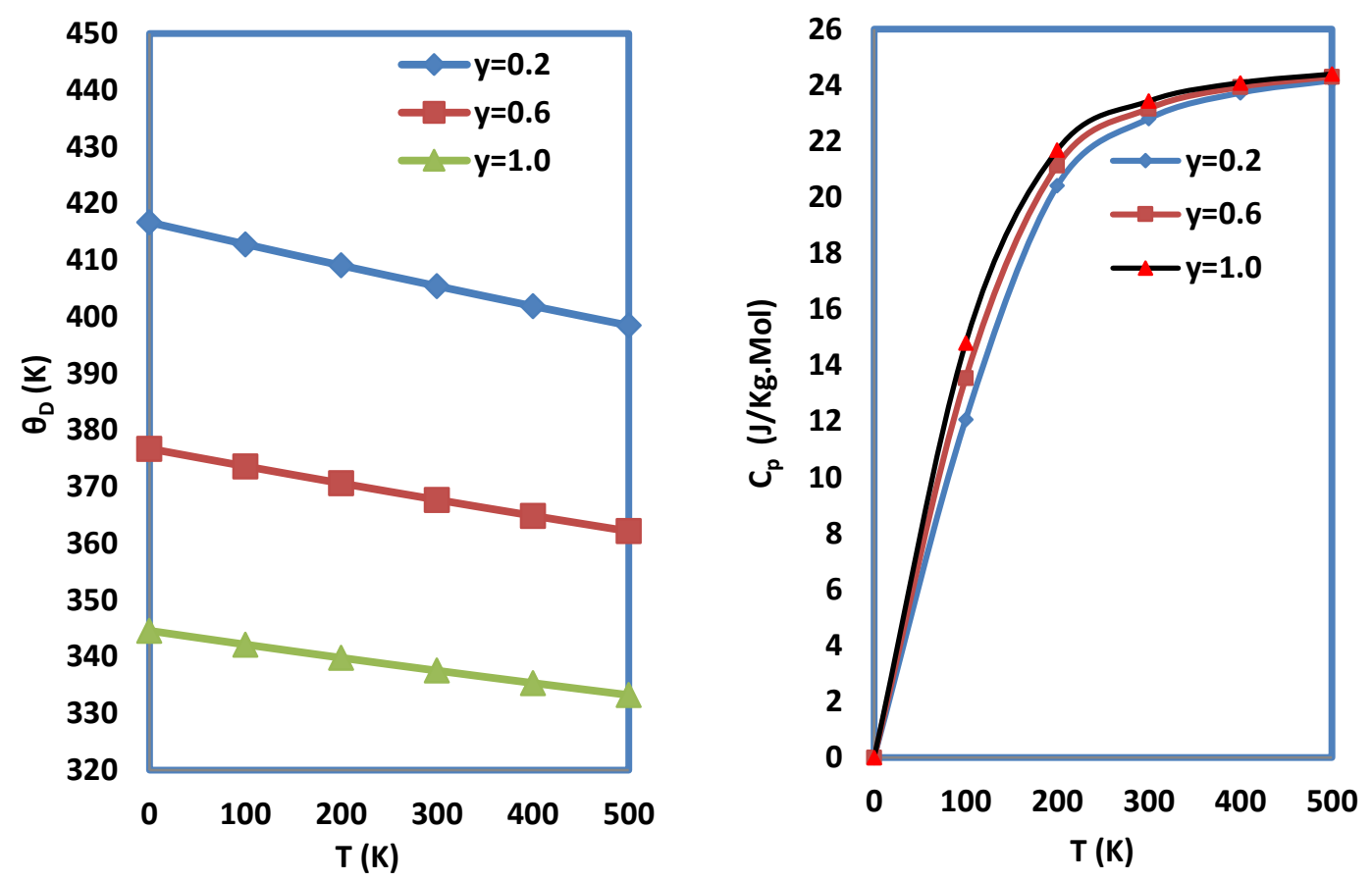

Fig. 6 The Debye temperature and the molar specific heat for $\operatorname{InP}_{x} A s_{y} S_{1-x-y} / I n A s$ system with temperature at certain values of compositions $(0.2,0.6$, and 1$)$

\section{Conclusion}

A study of some optoelectronic properties, thermal properties, phonon frequencies, mechanical properties, and acoustic velocities for the $\mathrm{InP}_{\mathrm{x}} \mathrm{As}_{\mathrm{y}} \mathrm{Sb}_{1-\mathrm{x}-\mathrm{y}} / \mathrm{InAs}$ system has been studied. The variation of the studied quantities with temperature from $(0-500 \mathrm{~K})$ for composition $(0.2,0.6$, and 1$)$ has been determined. Our calculations for the considered alloy lattice-matched to InAs substrate are in good agreement with the available experimental values. The calculated results in the present study seem likely to be convenient as a reference for future experimental work, especially at high temperatures. 


\section{Author contributions}

Degheidy and Elkenany designed research; Degheidy and AbuAli performed research; and Degheidy, Elkenany, and AbuAli wrote the paper. All authors have read and approved the final manuscript 
Data Availability Statement This manuscript has no associated data or the data will not be deposited [Authors' comment: This review has no associated data as all data discussed has been published elsewhere.]

\section{References}

Adachi, S.: GaAs, AlAs, and Al x Ga1-x As: Material parameters for use in research and device applications. J. Appl. Phys. 58, R1-R29 (1985)

Adachi, S.: Properties of Group-iv, III-v and II-VI Semiconductors. John Wiley \& Sons 
Adachi, S.: Properties of semiconductor alloys: group-IV, III-V and II-VI semiconductors. John Wiley \& Sons (2009)

Algarni, H., Al-Hagan, O.A., Bouarissa, N., Alhuwaymel, T.F., Khan, M.A.: Elastic constants and mechanical stability of In x Al1- x As y Sb1- y lattice-matched to different substrates. Philos. Mag. 98, 2582-2594 (2018)

Baranowski, J.M.: Bond lengths, force constants and local impurity distortions in semiconductors. J. Phys. C Solid State Phys. 17, 6287 (1984)

Bouarissa, N.: Compositional dependence of the elastic constants and the Poisson ratio of GaxIn1-xSb. Mater. Sci. Eng. B. 100, 280-285 (2003)

Boucenna, M., Bouarissa, N., Mezrag, F.: Composition and lattice mismatch dependent dielectric constants and optical phonon modes of InAs $1-x-$ ySbxPy quaternary alloys. Infrared Phys. Technol. 67, 318-322 (2014)

Chelikowsky, J.R., Cohen, M.L.: Nonlocal pseudopotential calculations for the electronic structure of eleven diamond and zinc-blende semiconductors. Phys. Rev. B. 14, 556 (1976)

Chen, D., Ravindra, N.M.: Pressure dependence of energy gap of III-V and II-VI ternary semiconductors. J. Mater. Sci. 47, 5735-5742 (2012)

Davydov, S.Y., Tikhonov, S.K.: Pressure dependence of the dielectric and optical properties of wide-gap semiconductors. Semiconductors. 32, 947-949 (1998)

Degheidy, A.R., Elabsy, A.M., Abdelwahed, H.G., Elkenany, E.B.: Pressure dependence of the electronic structure in $\mathrm{Ge}, \mathrm{GaP}$ and $\mathrm{InP}$ semiconductors at room temperature. Indian J. 
Phys. 86, (2012). https://doi.org/10.1007/s12648-012-0059-5

Degheidy, A.R., Elkenany, E.B.: Effect of pressure and temperature on electronic structure of $\mathrm{GaN}$ in the zinc-blende structure. Semiconductors. 45, (2011).

https://doi.org/10.1134/S106378261110006X

Degheidy, A.R., Elkenany, E.B.: Effect of temperature and pressure on the electronic structure of GaxIn1- xAsyP1- y alloys lattice matched to GaAs substrate. Mater. Chem. Phys. 143, 1-10 (2013)(a)

Degheidy, A.R., Elkenany, E.B.: Electronic and optical properties of InAs1-xPx alloys under the effect of temperature and pressure. Thin Solid Films. 539, 365-371 (2013)(b)

Degheidy, A.R., Elkenany, E.B.: Electronic, optical, and mechanical properties of BN, AlN, and InN with zinc-blende structure under pressure. Chinese Phys. B. 26, (2017). https://doi.org/10.1088/1674-1056/26/8/086103

Degheidy, A.R., Elkenany, E.B., Alfrnwani, O.A.: Temperature and Pressure Dependence of Elastic Constants and Related Parameters for InP Semiconductor. Silicon. 9, (2017). https://doi.org/10.1007/s12633-016-9408-x

Degheidy, A.R., Elkenany, E.B., Madkour, M.A.K., AbuAli, A.M.: Temperature dependence of phonons and related crystal properties in InAs, InP and InSb zinc-blende binary compounds. Comput. Condens. Matter. 16, e00308 (2018)

Elkenany, E.B.: Theoretical investigations of electronic, optical and mechanical properties for $\mathrm{GaSb}$ and $\mathrm{AlSb}$ semiconductors under the influence of temperature. Spectrochim. Acta Part A Mol. Biomol. Spectrosc. 150, 15-20 (2015)

Harrison, W.A.: Electronic Structure and the Properties of Solids WH Freeman. New York. 
Kittel, C., McEuen, P.: Introduction to solid state physics. Wiley New York (1976)

Moss, T.S.: A relationship between the refractive index and the infra-red threshold of sensitivity for photoconductors. Proc. Phys. Soc. Sect. B. 63, 167 (1950)

Pandey, K.C., Phillips, J.C.: Nonlocal pseudopotentials for Ge and GaAs. Phys. Rev. B. 9, 1552 (1974)

Pugh, S.F.: XCII. Relations between the elastic moduli and the plastic properties of polycrystalline pure metals. London, Edinburgh, Dublin Philos. Mag. J. Sci. 45, 823-843 (1954)

Saib, S., Bouarissa, N., Rodríguez-Hernández, P., Muñoz, A.: First-principles study of highpressure phonon dispersions of wurtzite, zinc-blende, and rocksalt AlN. J. Appl. Phys. 103, 13506 (2008)

Samara, G.A.: Temperature and pressure dependences of the dielectric constants of semiconductors. Phys. Rev. B. 27, 3494 (1983)

Shen, S.-G.: Calculation of the elastic properties of semiconductors. J. Phys. Condens. Matter. 6, 8733 (1994)

Vegard, L.: Die konstitution der mischkristalle und die raumfüllung der atome. Zeitschrift für Phys. 5, 17-26 (1921)

Wang, H.Y., Cao, J., Huang, X.Y., Huang, J.M.: Pressure dependence of elastic and dynamical properties of zinc-blende $\mathrm{ZnS}$ and $\mathrm{ZnSe}$ from first principle calculation. arXiv Prepr. arXiv1204.6102. (2012) 
Yang, M., Shao, L., Duan, J.-M., Chen, X.-T., Tang, B.-Y.: Temperature dependence of mechanical and thermodynamic properties of $\mathrm{Ti}(25+\mathrm{x}) \mathrm{Zr} 25 \mathrm{Nb} 25 \mathrm{Ta}(25-\mathrm{x})(\mathrm{x} \leq 20)$ refractory high entropy alloys: Influences of substitution of Ti for Ta. Phys. B Condens. Matter. 412851 (2021)

Zhang, X., Ying, C., Li, Z., Shi, G.: First-principles calculations of structural stability, elastic, dynamical and thermodynamic properties of $\mathrm{SiGe}, \mathrm{SiSn}, \mathrm{GeSn}$. Superlattices Microstruct. 52, 459-469 (2012) 